\title{
Lipid Profile Pattern in Type 2 Diabetes Mellitus Patients
}

\author{
Sultana MS ${ }^{1}$, Akhter $\mathrm{Y}^{2}$, Parvin $\mathrm{M}^{3}$, Alam MMU ${ }^{4}$, Naznin $\mathrm{L}^{5}$, Wahab MA ${ }^{6}$
}

DOI: https://doi.org/10.3329/jafmc.v14i2.45903

\begin{abstract}
Introduction: Dyslipidemia has been noted to play an integral role in the pathogenesis and progression of micro and macrovascular complications in Diabetes Mellitus (DM) patients. Lipid profile is the indicators of dyslipidemia.
\end{abstract}

Objectives: To evaluate the prevalence and pattern of dyslipidemia in type 2 DM patients.

Materials and Methods: This cross sectional study was conducted at Armed Forces Institute of Pathology (AFIP) from November 2014 to October 2015. The study included 300 type 2 diabetic patients belonging to the age group 30-59 years. Personal data and history of co-existing medical conditions were collected by data collection sheet and analyzed.

Results: Among 300 study subjects with type 2 DM the prevalence of dyslipidemia was $94 \%$ among them $19 \%$ had single dyslipidemia and $75 \%$ had multiple dyslipidemia. In this study, high level of total cholesterol (TC), triglycerides(TG) and Low Density Lipoprotein-Cholesterol (LDL-C) were found in $47.3 \%$, $76.7 \%$ and $41.3 \%$ patients respectively. High Density LipoproteinCholesterol (HDL-C) levels were found to be low in $60 \%$ patients.

Conclusion: The study revealed that dyslipidemia is very common in type 2 diabetic patients and the most common abnormality observed was increased serum TG level followed by decreased HDL-C level. So, patients with type 2 DM should be followed up with serum lipid profile regularly.

Key-words: Type 2 Diabetes mellitus, Dyslipidemia, Lipid profile.

\section{Introduction}

Dyslipidemia has been noted to play an integral role in the pathogenesis and progression of micro and macrovascular complications in Diabetes Mellitus (DM) patients. DM is a clinical syndrome characterized by hyperglycemia due to absolute or relative deficiency of insulin. DM is one of the most common chronic disease affecting the major population around the world'. Dyslipidemia is an important component of the metabolic syndrome observed in type ${ }^{2}$ diabetes patient and is characterized by moderate hypertriglyceridemia and low level of High Density LipoproteinCholesterol (HDL-C)2. On the other hand, worsening of glycemic control deterioratesthis dyslipidemia along with elevated Total Cholesterol (TC) and Low Density Lipoprotein-Cholesterol (LDL-C)². Lipid profile is the main indicators of dyslipidemia. Diabetes mellitus with poor glycemiccontrol is an important risk factor for atherosclerosis and coronary heart disease. Atherosclerosis accounts for up to $80 \%$ of deaths in diabetic patients due to coronary heart disease (CHD) and cerebrovascular or peripheral vascular disease ${ }^{3}$. To evaluate the prevalence and pattern of dyslipidemia in type 2 DM patients attending in Armed Forces Institute of Pathology (AFIP) for estimation of serum lipid profile and determination of frequency and pattern of dyslipidemia among the study subjects.

\section{Materials and Methods}

Thiscross sectional study was conducted AFIP from November 2014 to October 2015. A total of 300 patients were selected by non probability sampling method and all appropriate investigations were done. Individuals who have fasting plasma glucose (FPG) $\geq 7 \mathrm{mmol} / \mathrm{L}$ and age range 30-59 years were included in this study. Individuals known to have pregnancy, hypothyroidism, liver disease, kidney disease, malignant disease and on lipid lowering drug were excluded from the study. According to the executive summary of the third report of National Cholesterol Education Program-Adult Treatment Panel III (NCEP - ATP III)4, serum total cholesterol, LDL-C and HDL-C levels aretotal cholesterol <200 mg/dl: desirable, $200-239 \mathrm{mg} / \mathrm{dl}$ : borderline high, $\geq 240 \mathrm{mg} / \mathrm{dl}$ : high; LDL Cholesterol $<100 \mathrm{mg} /$ dl: optimal, $100-129 \mathrm{mg} / \mathrm{dl}$ : near or above normal, $130-159 \mathrm{mg} /$ dl: borderline high, 160-189 mg/dl: high, $\geq 190 \mathrm{mg} / \mathrm{dl}$ : very high; HDL Cholesterol $<40 \mathrm{mg} / \mathrm{dl}$ : low and $\geq 60 \mathrm{mg} / \mathrm{dl}$ are considered ashigh. The American Heart association5 recommends the following guideline for blood triglycerides level: <150 mg/dl: normal range, 150-199 mg/dl: borderline high, $200-499 \mathrm{mg} / \mathrm{dl}$ : high and $\geq 500 \mathrm{mg} / \mathrm{dl}$ are considered as very high. In this study individuals having TC: $>200 \mathrm{mg} / \mathrm{dl}$, TG: $>150 \mathrm{mg} / \mathrm{dl}, \mathrm{HDL}-\mathrm{C}:<40$ $\mathrm{mg} / \mathrm{dl}, \mathrm{LDL}-\mathrm{C}:>130 \mathrm{mg} / \mathrm{dl}$ are considered as dyslipidemia. After selection of appropriate study subject, informed written consent was taken from all the participant. Subjects were distributed according to different levels of lipid profile parameters; pattern of lipid profile were expressed as percentage. Unpaired t-test and proportion test were used to compare the result between male and female and among different age groups. $P$ values $<0.05$ was accepted as level of significance. Data have been analyzed by SPSS for Windows 18.0.

1. Lt Col Most. Sarmin Sultana, MBBS, MCPS, FCPS, Associate Professor Biochemistry, AFMC, Dhaka (E-mail: drsarmin101050@yahoo.com) 2. Brig Gen Yasmin Akhter, MBBS, DCP, FCPS, Classified Specialist in Pathology, CMH, Bogura 3. Brig Gen Mimi Parvin, MBBS, MCPS, DCP, FCPS, Professor of Biochemistry, AFMC, Dhaka 4. Lt Col Md. Mahbub UI Alam, MBBS, DA, FCPS, Classified Specialist in Anaesthesiology, CMH, Dhaka 5. Lt Col Lubna Naznin, MBBS, MCPS, DCP, FCPS, Classified Specialist in Pathology, AFIP 6. Lt Col Md Abdul Wahab, MBBS, MD, Associate Professor of Biochemistry, AFMC, Dhaka. 


\section{Results}

In this study among the 300 study individuals' prevalence of dyslipidemia (at least one abnormal lipid fraction) was 282(94\%) (Figure-1). Single dyslipidemia was in 57 (19\%) and $225(75 \%)$ had multiple dyslipidemia (Table-I). High level of serum TC, TG and LDL-C were found in 142 (47.3\%), 230 $(76.7 \%)$ and $124(41.3 \%)$ patients respectively and HDL-C levels were found to be low in $180(60 \%)$ patients. There was no significant difference $(p>0.05)$ of serum TC, TG andLDL-C level between male and female but significant difference $(p<0.05)$ was found in HDL-C level (Table-II). There was no significant difference $(p>0.05)$ of serum TC, TG andHDL-C level among different age groups but significant difference $(p<0.05)$ was found in LDL-C level (Table-III).

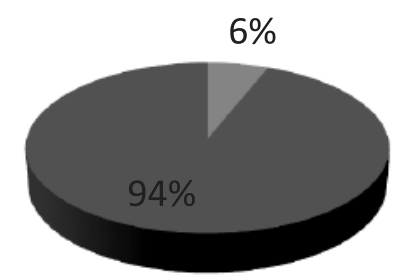

Normal

Dyslipidemia

Figure-1: Distribution of dyslipidemia in percentage $(n=300)$

Table-I: Pattern of single and multiple dyslipidemia $(n=282)$

\begin{tabular}{|l|l|c|c|}
\hline \multicolumn{2}{|l|}{ Characteristics } & Number & Percentage \\
\hline \multirow{4}{*}{$\begin{array}{l}\text { Single } \\
\text { Dyslipidemia: }\end{array}$} & High TG & 34 & 59.6 \\
\cline { 2 - 4 } & Low HDL-C & 20 & 35.1 \\
\cline { 2 - 4 } & Others & 3 & 5.3 \\
\cline { 2 - 4 } & Total & 57 & 100 \\
\hline \multirow{4}{*}{$\begin{array}{l}\text { Multiple } \\
\text { Dyslipidemia: }\end{array}$} & High TG \&low HDL-C & 80 & 35.6 \\
\cline { 2 - 4 } & High TG, high TC \& high LDL-C & 50 & 22.2 \\
\cline { 2 - 4 } & High TG,high TC, high LDL-C \& low HDL-C & 44 & 19.6 \\
\cline { 2 - 4 } & Others & 51 & 22.6 \\
\cline { 2 - 4 } & Total & 225 & 100 \\
\hline
\end{tabular}

Table-II: Distribution pattern of lipid profile in male and female $(n=300)$

\begin{tabular}{|c|c|c|c|c|}
\hline \multicolumn{2}{|l|}{ Parameter } & Male $\mathrm{n}(\%)$ & Female $\mathrm{n}(\%)$ & $p$ value \\
\hline \multirow{4}{*}{ Serum TC (mg/dl) } & $<200$ & $76(50.7)$ & $82(54.7)$ & \multirow{4}{*}{$>0.05$} \\
\hline & $200-239$ & $44(29.3)$ & $50(33.3)$ & \\
\hline & $\geq 240$ & $30(20.0)$ & $18(12.0)$ & \\
\hline & Total & $150(100)$ & $150(100)$ & \\
\hline \multirow{5}{*}{ Serum TG(mg/dl) } & $<150$ & $32(21.3)$ & $38(25.3)$ & \multirow{5}{*}{$>0.05$} \\
\hline & \begin{tabular}{|l|}
$150-199$ \\
\end{tabular} & $40(26.7)$ & $36(24.0)$ & \\
\hline & $200-499$ & $72(48.0)$ & $70(46.7)$ & \\
\hline & $\geq 500$ & $6(4.0)$ & $6(4.0)$ & \\
\hline & Total & $150(100)$ & $150(100)$ & \\
\hline \multirow{4}{*}{ Serum HDL-C(mg/dl) } & $<40$ & $98(65.3)$ & $82(54.7)$ & \multirow{4}{*}{$<0.05$} \\
\hline & $40-59$ & $52(34.7)$ & $64(42.7)$ & \\
\hline & $\geq 60$ & 0 & $4(2.7)$ & \\
\hline & Total & $150(100$ & $150(100)$ & \\
\hline \multirow{6}{*}{ Serum LDL-C(mg/dl) } & $<100$ & $44(29.3)$ & $44(29.3)$ & \multirow{6}{*}{$>0.05$} \\
\hline & $100-129$ & $42(28.0)$ & $46(30.7)$ & \\
\hline & $130-159$ & $38(25.3)$ & $44(29.3)$ & \\
\hline & $160-189$ & $18(12.0)$ & $8(5.3)$ & \\
\hline & $\geq 190$ & $8(5.3)$ & $8(5.3)$ & \\
\hline & Total & $150(100)$ & $150(100)$ & \\
\hline
\end{tabular}

Table-III: Distribution pattern of lipid profile in different age groups $(n=300)$

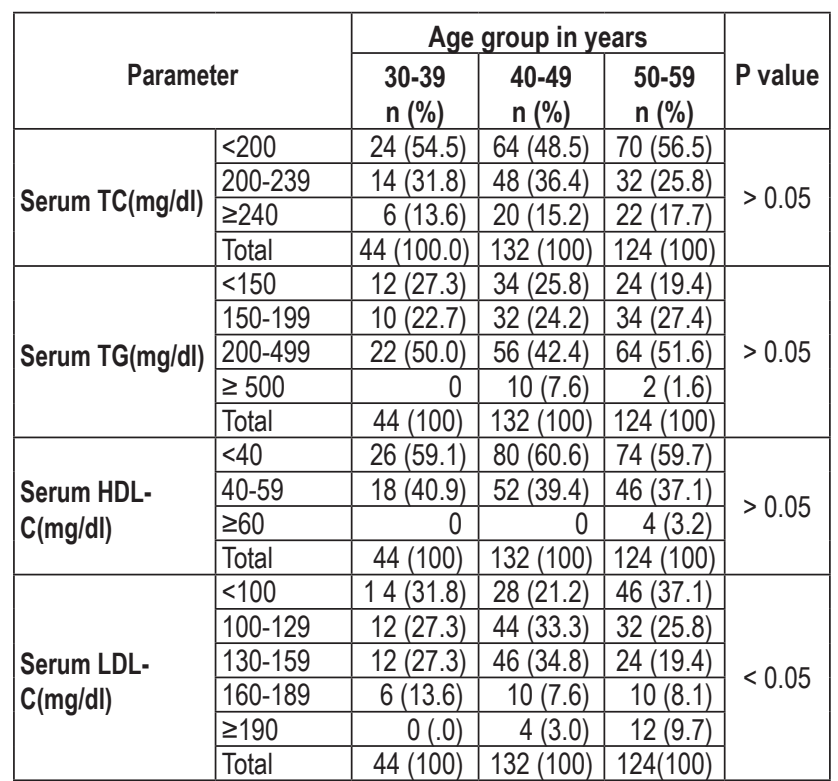

\section{Discussion}

This study provided the evidence for the presence of high prevalence of dyslipidemia in type 2 diabetic patients. Dyslipidemia was found to be highly prevalent in this study (94\%). This was similar to the observation in South Africa where a prevalence of $90.3 \%$ was reported ${ }^{6}$. This results appeared relatively higher compared with $60.5 \%$ overall prevalence in Nigeria by Onuigbo et $\mathrm{al}^{7}$. This study finding is supported by CDC, reporting of $97 \%$ of adults with diabetes have one or more lipid abnormalities ${ }^{5}$. In this study $76.7 \%$ had hypertriglyceridemia which is higher than the study by Udawat et al. where hypertriglyceridemia was observed in $54.5 \%$ cases $^{8}$. Similarly Sarkar et al in 2009 in Dhaka, Bangladesh showed the hypertriglyceridemia in 58\% type 2 diabetic patients ${ }^{9}$. But this study matched with the study in Pakistan in 2011 which showed hypertriglyceridemia in 78\% cases $^{10}$. In this study $60 \%$ patients had low HDL-C. This study is consistent with the study of Onuigboet $\mathrm{al}^{7}$, they found that $62 \%$ of type 2 diabetic patient had low HDL-C. Study by Singh and $\mathrm{Kumar}^{11}$ found $89 \%$ of type 2 diabetic patients with low HDL-C which is higher than this finding. The lifestyle, food habit, occupation may account for these differences.

In this study, there was significant difference $(p<0.05)$ in serum HDL-C level between male and female. The female sex hormone estrogen tends to raise $\mathrm{HDL}$ cholesterol, and as a rule, women have higher HDL (good) cholesterol levels than men. Estrogen production is highest during the childbearing years. This may help explain why premenopausal women are usually protected from developing heart disease ${ }^{5}$. Fatma and Najah ${ }^{12}$ in 2005 showed in their study hypercholesterolemia in $48 \%$ patients and our study $47.3 \%$ type 2 diabetic patient had hypercholesterolemia. Similarly, Sarkar et al $^{9}$, in 2009 in Dhaka, Bangladesh found hypercholesterolemia in 41\% type 
2 diabetic patients. Haq AU1', in 2006 in Peshawar showed in their study that serum cholesterol was above the normal value in $60 \%$ of the subjects in the obese group and it was more than normal in $56 \%$ of the subjects in the non-obese group.

This difference in cholesterol level may be due to fact that it depends on other factors like dietary habit, weight, sex, age and others. No significant difference was observed between serum cholesterol level in respect of different age groups or sex. In this study we found increased LDL-C in $41.3 \%$ of diabetic patients but study in Karachi' ${ }^{13}$ in 2009 showed increased LDL-C in $83 \%$ and Sultan, et $\mathrm{al}^{12}$ in Kuwait $72 \%$. This study did not match with their study which may be due to some factor in our population like lesser body mass index and relatively poor cholesterol containingdiet ${ }^{14}$. The commonest form of multiple dyslipidemia was hypertriglyceridemia with low HDL-C. The results of the present study were in agreement with the previous research reports that in type 2 diabetes the major disturbances in lipoprotein metabolism are reflected by an increase in plasma triglyceride and a low HDL-C with normal or near normal LDL-Cholesterol levels ${ }^{15,16}$.

\section{Conclusion}

The study revealed that dyslipidemia is very common in type 2 diabetics and the most common abnormality observed was increased serum triglyceride levels followed by decreased serum high-density lipoprotein cholesterol (HDL-C) levels. So, patients with type $2 \mathrm{DM}$ should be followed up with serum lipid profile at regular intervals.

\section{References}

1. Haq AU, Rahman JU, Mahmud R, Safi AJ, Ahmed Z, Arif S. Pattern of lipid profile in type 2 diabetes mellitus patient. JPMI 2006; 20(4):366- 9

2. Grundy SM. Hypertriglyceridemia, insulin resistance and the metabolic syndrome. AM JCardial 1999; 83(9B); 25F-29F

3. Ahmed N, Khan J, Siddiquei TS. Frequency of dyslipidaemia in type 2 diabetes mellitus in patients of Hazaradivision. JAMC 2008; 20(2):51-3.

4. Executive summary of the third report of the National Cholesterol Education program(NCEP) Expert panel on Detection, Evaluation, and Treatment of High Blood Cholesterol in Adults (Adult treatment panel III). JAMA 2001; 285:2486-97.

5. Morag NK, Eran C, Gold B. High blood triglycerides are independent risk factors for stroke. American Heart Association's 2002; 26:6-7.

6. Onat A, CanG, Kaya H, Hergenc G. "Atherogenic index of plasma" (log10triglyceride/high-density lipoprotein cholesterol) predicts high blood pressure, diabetesand vascular events. Journal of Clinical Lipidology 2010; 4:89-98.

7. Onuigbo NNJ, Unuigbe El, Oguijiofor. Dyslipidaemia in type 2 diabetes mellitus patient in Nnewi SOUTH-East Nigeria. Annals of African medicine 2011; 10(4):285-9.

8. Udawat H, Goyal RK, Maheshwari S. Coronary Risk and Dyslipidaemia inType-2 Diabetic Patients. Assoc Physic India 2001; 3(1):38-40.

9. Sarkar BC, Sana NK, Sarker GK et al. Serum Lipid Profile of Type2 Diabetic Patients in the Dhaka city of Bangladesh. Research \& Reviews in Bio Sciences 2009; 3.

10. Sultana R, ParveenN, Khan GJ et al. Study of Lipoprotein Patient as an Atherogenic Factor in Type 2 Diabetes Mellitus. J. Med. Sci $2011 ; 19: 70-3$.

11. Sing G, Kumar AK. A Study of Lipid Profile in Type 2 Diabetic Punjabi Population. Journal of Exercise Science and Physiotherapy 2012;8(1):7-10

12. Fatma AA, Najah A. Clinical Epidemiology of Type 2 Diabetes Mellitus in Kuwait. Kuwait Medical Journal 2005; 37(2):98-104.

13. Bhatti SM, Dhakam S, Khan A.Trends of iipid abnormalities in Pakistani type 2 diabetes mellitus patients: A tertiary care centre data. Pak J Med Sci 2009; 25(5):883-9.

14. Saha D, Rahman ASMM, AH MS. Lipid profile pattern in different age groups of healthyadult armed forces personnels of Dhaka cantonment. Bangladesh J Physiol and Pharmacol 1999; 15(2):43-6.

15. Ahmed N, Khan J, Siddiqui TS. Frequency of Dyslipidemia in type 2 Diabetes Mellitus inpatients of Hazara division. J Ayub Med Coll Abbottabad 2008; 20(2):51-4

16. Arshag D. Dyslipidemia in type 2 diabetes mellitus. Clinical Practice Endocrinology and Metabolsm 2009; 5:150- 9. 